\title{
SUSPENSIÓN DE GÉNERO: TRAVESTISMO Y LA CUESTIÓN DE LO TRANS EN SALÓN DE BELLEZA (1999)
}

\section{SUSPENDING GENDER: TRANSVESTISM AND TRANSNESS IN SALÓN DE BELLEZA (1999)

\author{
JORGE SÁNCHEZ CRUZ'
}

\footnotetext{
${ }^{1}$ Universidad de Pennsylvania, Estados Unidos.
}

Correo electrónico: jorgesc1@sas.upenn.edu

\begin{abstract}
Resumen
Este artículo explora los modos en que Salón de belleza (1999), de Mario Bellatin, propone una suspensión de las reglas de género. Mediante una lectura enfocada en la alteración del binario heteronormativo, se propone que el texto está narrado por una persona trans que oscila y desestabiliza las identidades de género, demostrando también que el travestismo opera como otro modo de imaginar el mundo. Pasando por la argumentación sobre lo trans* de Jack Halberstam y una teoría travesti-trans de Marlene Wayar, el artículo culmina al apostar a imaginar otro mundo de posibles, ahí donde lo trans y lo travesti movilizan y reconfiguran las esferas de lo social.
\end{abstract}


Palabras clave: trans, travestismo, performance, género, literatura

\begin{abstract}
This article explores the ways in which Salón de belleza (1999)

by Mario Bellatin suspends the rules of gender. Through a reading that emphasizes a destabilization of the heteronormative binary, I propose that the text is narrated by a trans subject, who oscillates and alters the identitarian logic, and who unveils how transvestism operates as an alternative worldbuilding strategy. Through Jack Halberstam's contention of transness and Marlene Wayar's vision of a travesti-trans theory, this article culminates in thinking of other means of imagining worldly possibilities, wherein trans and travesti life can mobilize and reconfigure the social sphere.
\end{abstract}

Keywords: trans, transvestism, performance, gender, literature

ReCEPCIÓN: 14 DE NOVIEMBRE DE 2020/ACEPTACIÓN: 10 DE FEBRERO DE 2021

\title{
INTRODUCCIÓN
}

Salón de belleza es un relato narrado en primera persona

por una voz anónima, sin nombre o identidad, cuya vida ha sido afectada por un virus (especulativamente el VIH) 
diseminándose por el cuerpo social. Mientras cierta crítica ha enfocado la mirada en la dispersión patogénica y sus efectos corporales que el texto refleja (Delgado, 2011; Vaggione, 2009; Meruane, 2012, pp. 191-226), este trabajo explora los modos en que, antes y después de la invasión viral, el texto lleva en su interior una suspensión de las reglas normativas de género. Mediante una lectura enfocada en la alteración del binario heteronormativo, propongo que el texto es narrado por una persona trans, que oscila y desestabiliza las identidades de género, y demuestra también que el travestismo opera como otro modo de imaginar y estar en el mundo. Así, desde la manifestación de lo trans y de lo travesti, el texto opera como un cianotipo para pensar la desarticulación de las reglas de género, abriendo así, en el campo literario, un movimiento que interroga los límites de sexo y género.

\section{LA CUESTIÓN DE LO TRANS}

El texto de Mario Bellatin está narrado por una persona cuya identidad es desconocida. Sin embargo, en el interior del texto, la voz narradora menciona haberse escapado de la casa a muy temprana edad porque su madre nunca le "perdonó que no fuera el hijo recto con que ella soñaba" (Bellatin, 1999, p. 45). Es en este momento, en la huida del núcleo familiar, donde el protagonista de la novela instaura una línea de fuga de las expectativas de género, ahí 


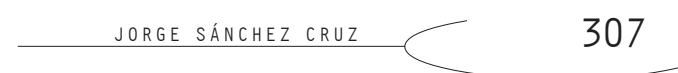

donde cada sujeto familiar debe replicar y adherirse a las expectativas de la reproducción normativa. ${ }^{2}$ Si bien se ha señalado que la razón

${ }^{2}$ Ver Líneas de Fuga. Por otro mundo de posibles (2013), de Félix Guattari. reproductiva asegura la continuación de la especie mediante la figura del niño/hijo, ${ }^{3}$ como también en la protección y la nutrición de la vida misma - esto es el movimiento pro-vida, por ejemplo- ${ }^{4}$ el texto de Mario Bellatin presenta a una persona disidente como línea desestabilizadora, desterrándose a sí misma para generar otro tipo de vida y otro tipo de mundo. El personaje principal, entonces, transita de su casa a un hotel al norte del país, donde trabaja hasta los veintiún años; ahí genera otro tipo de vínculo, es decir, otro modo de hacer "familia" con el dueño hotelero que lo "trataba con cariño" (Bellatin, 1999, p. 46), después inaugura un salón donde con otros sujetos no-normativos crean una afinidad travesti-trans. Este transitar - de pasar y de moverse geográficamente, como también de pasar de un núcleo a otropuede llegar a percibirse como desestabilización de las normas de género. Transitar, traspasarse y transgredir las pautas de lo sexual (apegado al marco cristiano-católico de la familia) y sus expectativas instaura la cuestión de lo trans. Quiero proponer el prefijo trans no solo como registro lingüístico que denota una continua transición, sino también como modo de ser, de corporeizar diferencia, de generar otras afinidades 
${ }^{5}$ Ver The Feeling of Kinship (2010) de David Eng o Animacies (2012) de Mel Chen. Kinship, en estos aspectos, va más allá de la lógica heterosexual de

hacer familia; por ejemplo, se trata de núcleos alternativos entre drag queens, entre personas trans o disidentes sexuales en general. (kinship, en términos de América del Norte) ${ }^{5}$ y de hacer de los límites de sexo y de género fronteras porosas.

Jack Halberstam ha propuesto el termino trans* (con asterisco) "precisely to open the term up to unfolding categories of being organized around but not confined to forms of gender variance" ["precisamente para abrir el término a categorías organizantes en desarrollo no confinadas a formas de variantes de género]" (2017,

${ }^{6}$ Todas las traducciones al español son propias. $\mid$ p. 4) ${ }^{6}$ Del mismo modo, el asterisco "modifies the meaning of transitivity by refusing to situate a transition in relation to destination, a final form, a specific shape, or an established configuration of desire and identity" ["modifica el significado de la transitividad al negarse a situar tal transición en relación con un destino, en una forma final, un molde en específico o una configuración establecida de deseo e identidad"] (p. 5). Es decir, el asterisco cancela todo tipo de definición identitaria de lo sexual por venir (en materializarse) y, más importante, enfatiza el teórico estadounidense, deja que las personas trans* sean autores de sus propias categorizaciones (p. 5). El termino trans*, en este sentido, está en disputa y en tensión con las variantes de género que han pronunciado definiciones estáticas, pronunciamientos médicos y exclusiones sociales violentas.

Del mismo modo, Marlene Wayar propone una "teoría travestitrans Sudamericana" enfocada en "comenzar a accionar en vistas 
una transformación antropológica que nos devuelva autonomía, que nos devuelva la confianza necesaria para una crianza con amor responsable, lejos de toda banalidad" (2019, p. 17). También, la activista y teórica cultural argentina enfatiza que la infancia es una "potencia inusitada": "el momento y el espacio adecuados y oportunos para la indagación, la transformación y la identificación" (p. 18). Wayar agrega, más adelante, que la idea es "la infancia como ese tiempo y cartografía donde podemos construir una tercera opción a la dicotómica propuesta entre identidad/Yo-Otredad, el poder como posibilidad de construir Nostredad, posibilidad valiosa para enarbolar nuestras voces" (p. 25). Esa "tercera opción" es una subjetividad travesti y trans que va más allá del binario hombre-mujer y que puede emerger a construirse desde la infancia (tal como el personaje de Salón de belleza), generando un "voy siendo travesti" (p. 25), un desarreglo continuo del heteropatriarcado que se explaya para configurar otro modo de habitar el mundo. Por eso, si para Halberstam lo trans* altera y rechaza todas las variantes identitarias de género para apostar por otros tipos de seres, cuerpos y vitalidades, para Wayar un movimiento travestitrans tiene la posibilidad de comenzar a hacer un cambio desde la infancia, ahí donde une empieza a ser une misme, como también donde se puede comenzar a hacer parte de otres (una "Nostredad") que comparten las mismas experiencias con sus peculiares y singulares diferencias. ${ }^{7}$ Así pues, Halberstam enfatiza que lo trans*

${ }^{7}$ De aquí en adelante utilizo el registro neutral de género para marcar una des-identificación del binomio 
puede generar su propia historia a lo que Wayar se refiere en regresar a un estado de autonomía por medio de una transformación antropológica. Esta transformación interviene y cambia las tecnologías de cuerpo abisagradas a políticas identitarias estatales donde lo trans y lo travesti, constitutivamente relacionados (como lo sugiere Wayar) mas no en oposición, navegan y negocian en lo social.

En Salón de belleza, la voz trans comienza a generar su autonomía y su propia historia desde su niñez para después inaugurar un lugar estético como modo de supervivencia, lejos de su familia biológica y en contacto con otros sujetos que alteran las expectativas normativas de género. Incluso no hace mención a su padre biológico para hacer que el relato se mueva lejos de un orden heteropatriarcal. Por eso, en el salón se descubre que "unos estilistas [estaban] vestidos casi siempre con ropas femeninas" (Bellatin, 1999, p. 24) con quienes después genera vínculo para transitar la ciudad. Cabe recalcar que la voz narradora no refuta su identidad biológica dada al nacer, como tampoco se identifica completamente como "mujer" u "hombre." La ambigüedad de su identificación de género (al igual que la de sus compañeres), por un lado, es un silencio estratégico del texto que hace que el lector no asuma el género del otre posicionado enfrente de une misme y, por el otro, el desconocimiento del sexo y género del personaje principal abre una ventana a especular si tal sujeto está en transición a otro sexo no biológicamente dado. En otras palabras, ¿es posible 
acercarse al otre que posa diferente a une misme sin mediatizar tal acercamiento con un lente normativo de género? o, más bien, ¿cuáles son los otros saberes que yacen a partir de una lectura desembarazada de un binario heterosexual? Salón de belleza opera, en este aspecto, desde la ambigüedad: sin darle nombre al virus que recorre el texto y sin darle género ni identidad a sus personajes los cuales, especula el texto, están constreñidos por los registros del código civil estatal heredado de un poder colonial heterosexista que dejó un código patriarcal compulsivo - como se verá- en la formación del Estado-nación. ${ }^{8}$ Krzysztof Kulawik analiza que "los silencios, lo no dicho/escrito, [y] todas ver The Coloniality of Gender (2008) y Heterosexualism omisiones" (2009, p. 261) textuales en narrativas postmodernas apuesta a un travestismo lingüístico (p. 264) que descentra las máscaras de la identidad (p. 279); un "travestismo que pone en escena lo indeterminado y lo ambiguo" (p. 279). Salón de belleza pone en relieve este uso estratégico textual no solo para borrar las distinciones binarias de lo sexual sino también para ofrecer otro tipo de conocimiento: vacíos, silencios e incertidumbres que la máquina heteronormativa de género fracasa en regular.

La voz trans, en este aspecto, no tiene una "forma final" (p. 5), siguiendo a Halberstam, ni un deseo preconfigurado, es decir, su sexo y género no son identificables. Kulawik (2012) menciona este proceso como un "des-escribir" del hombre y de la mujer que genera algo indefinido "abierto a proceso de 
redefinirse de maneras múltiples con posibilidades infinitas" (2012, p. 176). De esta manera, mientras que Kulawik sintetiza la manera en que la obra de Bellatin presenta "una performance textual de las identidades indefinidas y transitorias" (2012, p. 177), Halberstam y Wayar proponen andamiajes teóricos y culturales que avanzan la posibilidad de transformar las estructuras sociales hetero-hegemónicas.

El texto de Bellatin saca a la luz a una persona trans que, en tono des-identificatorio (Muñoz, 1999, p.11), oscila estratégicamente -al igual que los sujetos travestis-trans del salón-por los dos polos de los sexos oficiales, para reflejar el modo en que vidas minoritarias trafican entre lo dominante y lo minoritario, entre lo que puede visibilizarse en la esfera pública y lo que tiene que esconderse para asegurar su continua sobrevivencia. El salón de belleza, por ende, es centro contestatario en el cual se hace inteligible un mundo subordinado que suspende el régimen de género. Dice la voz trans que, aunque el salón le hacía cumplir obligaciones, siempre “esperaba con ansiedad que llegaran los tres días de la semana que habíamos señalado para salir a la calle vestidos de mujer" (Bellatin, p. 47) [énfasis propio]. Menciona también: "Adoptamos la costumbre de vestirnos así para atender a las clientas, pues me pareció que de ese modo se creaba un ambiente más íntimo en el salón" (Bellatin, p. 47) [énfasis propio]. Si bien el yo de la voz trans refuta y se niega a identificarse bajo los registros lingüísticos normativos de género, al con- 
jurar la forma del nosotros, enunciando adoptamos y habíamos, lo trans deviene en una especie de multitud de cuerpos transgresivos que generan una intimidad trans y travesti, un nuevo modo de relacionarse con une misme (y con las clientas), otro modo de hacer comunidad y de hacer familia. Son, entonces, vidas trans y travestis (por exceder las identidades sexuales dicotómicas) que arman una "Nostredad" en el interior del salón y después este yo devenido plural reconfigura el espacio social mediante el travestismo.

\section{TRAVESTISMO}

Antes de la dispersión del VIH/SIDA, el relato ilumi-

na un proceso de subjetivación anclado en un régimen de género. Los recuerdos fragmentarios de la voz trans del salón, de un pasado reciente en la ciudad, señalan un mundo subordinado de lo sexualmente disidente. Cuenta la voz trans que durante el apogeo del salón adoptaron la costumbre de vestirse de mujer para crear un ambiente más íntimo (Bellatin, 1999, p. 47). Llegado el viernes, se preparaban para salir a las calles de la ciudad. Desde una zona marginada, ya que el salón está geográficamente ubicado en las orillas de la ciudad, la voz narradora y sus compañeres generan estrategias para navegar el centro de la ciudad: 
No podíamos viajar vestidos de mujer, pues en más de una ocasión habíamos pasado por peligrosas situaciones. Por eso guardábamos en los maletines los vestidos y el maquillaje que íbamos a necesitar en cuanto llegáramos a nuestro destino. Antes de esperar en alguna avenida transitada, ya travestidos nuevamente, ocultábamos los maletines en agujeros que había en la base de la estatua de uno de los héroes de la patria. (Bellatin, 1999, p. 24)

La voz trans describe cómo, de pasar de un espacio a otro, del salón a la urbe, siempre corrían el riesgo de enfrentarse a "peligrosas situaciones", encuentros violentos con la "Banda de Matacabros", que "rondaba por las zonas centrales de la ciudad" (Bellatin, 1999, p. 15). Inclusive "Muchos terminaban muertos después de los ataques de esos malhechores" (Bellatin, 1999, p. 15). El texto explica que este grupo antigay, pues "cabro" lleva consigo una connotación homofóbica, actúa ante la amenaza de la manifestación de cuerpos-sujetos que desbalancean las visualidades de lo normativo. En un manejo estratégico de los espacios, la voz trans contrapone el adentro del salón, en el cual sus amigues podían travestirse sin ninguna preocupación de discriminación, y el afuera, donde corrían el riesgo de enfrentarse a la violencia sexual. Este adentro ha de convertirse en un espacio de albergue para cuerpos expulsados del cuidado médico por ser, ante el contagio de un 


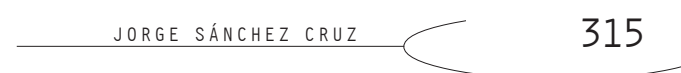

virus desconocido, una amenaza a la "salud" de la nación. Y es desde este espacio donde emerge un movimiento de lo travesti guiado por el deseo, aquello que el régimen del saber fracasa en capturar, transformando la polis por medio de otra circulación de cuerpos deseantes. Por medio del maquillaje, las plumas, los vestidos y los maletines escondidos debajo de las estatuas de los héroes nacionales, el texto, por una parte, saca a flote los usos estratégicos de lo travesti-trans atravesando los espacios de la formación social (Lefebvre, 1991, p. 33) y, por otra parte, visibiliza estar en relación con otros movimientos diferentes desplazándose por los espacios (de Certeau, 1984 , p. 474), otros sujetos y cuerpos (hetero)normativos, pero donde el primero queda sumergido en la clandestinidad.

De Certau agrega que en la práctica del día a día se hace visible el estatus de lo minoritario dominado por elementos mayoritarios de la sociedad (pp. 474-475). En efecto, saliendo del salón, esta corriente travesti se mueve, se desplaza e irrumpe estratégicamente los territorios dominantes, generando así una praxis movilizadora, contrarrestando la organización normativa (DiPietro, 2015, p. 686). Al atravesar la formación social y sus espacios, la movilización travesti produce una performatividad de transversalidad (Berkins: 2006), una corriente que "makes connections among travestis re-defining space and embodiment in transversal fashion" ["hace conexiones entre travestis para re-definir el espacio y el cuerpo en modo 

compañeres, en el exterior, en las calles y en la ciudad, potencializa hacer conexiones con otras vidas travestis y trans, incluso, podría decirse, una anti-relación con el poder normativo.

El andar travesti es un ritmo disidente que no solo re-cartografía los espacios dominantes (Berkins en DiPietro, 2015, p. 686) sino que revela otro circuito de cuerpos minoritarios navegando el territorio de un estado heteropatriarcal, un ensamblaje fundado por héroes nacionales heteromasculinos hipervisibilizados en el epicentro de la ciudad. Lado a lado con las imágenes icónicas de lo nacional, como menciona la cita, el transitar travesti deja en la monumentalización de estas figuras una fisura como apertura que apuesta hacia otra lucha de legitimización sexual exteriorizada por una patria normativizada. Si bien, como menciona Judith Butler, aquel cuerpo que resiste las normas está igualmente habilitado (1993, p. 15), en el (re)vestir travesti se encuentra no solo un fracaso en validar las expectativas de los sexos normales, sino un rechazo del ordenamiento de lo normalmente inteligible, apostando así a la futurización de otros cuerpos (trans)sexuales posibles. Así pues, no es coincidencia que la movilización temporal, al asaltar la urbe, deje su huella (simbólica y material) disidente en los agujeros de las estatuas de los héroes nacionales; afecto de deseo, nos dice Néstor Perlongher, aquello 


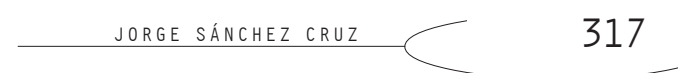

imprescindible en descifrar, negociado cotidianamente y desbordándose para transformar el espacio urbano (1999, pp. 6398).

El travestismo, entonces, es un acto que penetra la fundación del orden de la nación para volverlo en su revés. Simula un "original" - el otro sexo (lo femenino) - para recrear su ser; aparenta el regreso a su "original (lo masculino)" como motor de supervivencia para después volver a repetir la emulación del otro sexo (femenino) encubriendo su "original (lo masculino)". El travesti, menciona Severo Sarduy, converge tres posibilidades del mimetismo: "el travestimiento [...] que se precipita en la persecución de una irrealidad infinita, [...] ser cada vez más mujer"; el camuflaje como "especie de desaparición, de invisibilidad"; y "la intimidación, pues el frecuente desajuste o la desmesura [...] paralizan o aterran" (1982, p.14). El primero, apunta a ser más que una mujer "hasta sobrepasar el límite" (p.14), nos dice Sarduy, mientras que el segundo asegura hacerse pasar como el otro sexo - passing como modo de sobrevivencia-, ${ }^{10}$ y el ${ }^{10}$ Jasbir Puar en Bodies With New Organs (2015) último provoca miedo, incluso pánico $\begin{array}{r}\text { desarrolla el concepto de passing, una simulación } \\ \text { exacta por personas trans que opera como modo de }\end{array}$ precisamente porque, como menciona $\mid \begin{array}{r}\text { esquivar discriminación, violencia sexual e incluso } \\ \text { desaparición. }\end{array}$ Sylvia Molloy, aquello que posa como muy extravagante y excesivo desconcierta el ojo hetero-masculino (2012, pp. 41-54). Este último, como se ha mencionado arriba, resulta en la muerte de vidas travestis y trans. Por eso, entre la simulación y mimetización del otro sexo, el travestismo y lo trans van más 
allá de reproducir el binario de género, desbordando sus límites y subvirtiendo el modelo heteropatriarcal - "contra el padre" (Sarduy, 1982, p. 18) - para apostar a lo que "voy siendo" (Shock en Wayar, 2019, p. 25). En efecto, el travestismo invoca otro modo de vivir, "inaugura un giro epistemológico que localiza, define, performa y borra la dicotomía fundamental de Otro/Yo" (Sifuentes-Jáuregui, 2002, p. 4). Borroneando el binario establecido, el travestismo performa una desobediencia epistémica (DiPietro, 2016, p. 66) puesta en práctica por travestis que retoman las calles y sus esquinas. El cuerpo travestitrans transgrede los códigos taxonómicos normativos, develando al lector relatos y saberes sexo-disidentes que intensifican su agencia subversiva. ${ }^{11}$

Después de circular las avenidas principales, la voz trans nos adentra en los espacios subterráneos donde emana la explotación de sexo, deseo y trabajo travesti: "Había momentos en que nos cansaba tanto cambio de ropa, y si bien con eso no se ganaba dinero, buscábamos algo de diversión dentro de algunos cines donde proyectaban de manera continuada películas pornográficas. Los tres lo pasábamos bien cada vez que los espectadores iban al baño" (Bellatin, 1999, p. 24). Si bien la voz trans describe que "los tres" - en clave masculina-circulaban los deseos de los espectadores, detrás de esta descripción del yo pasándose como masculino se esconden 


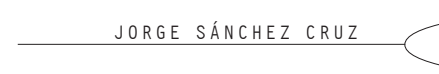

prácticas no normativas. ${ }^{12}$ Aquí simular no es un fingimiento (Baudrillard en Kulawik, 2012, p. 177), menos "un fingir lo que no se tiene" (Kuwalik, 2009, p. 264), más bien un ir y venir de ambos polos del binario normado para esquivar violencia, generar ganancia y potenciar vivencia.

En este sentido, el vaivén estratégico del yo trans no es solo un acto des-identificatorio de los dos polos de sexo, sino uno que termina desenvolviéndose en un acto performativo que resiste las expectativas materiales del cuerpo; esto es, guiado por un deseo de generar dinero que es placer por diversión y, simultáneamente, una re-mapear estratégico de la ciudad.

En estos ordenamientos, el travestismo, como capacitación de trabajo "prostibulario" desplazado en las zonas ciegas de la ciudad, devela otros modos de intercambio monetario cuya transacción de cuerpo por dinero manifiesta un modo alternativo al del aumento de la escala oficial de producción. En términos marxistas, la circulación del grupo travesti es un proceso de alienación que escapa el control racional del dinero y la acumulación. Un flujo de remuneración monetaria no asalariado enmarcado bajo otra lógica de producción que opera, podríamos decir, independientemente, pero en relación con el orden capitalista; socavando su centralización mediante un trabajo travesti, como se ha señalado, guiado por el deseo y 
el placer. De este modo, el sexo-servicio en las calles o en los cines clandestinos, es un vector laboral que produce desde

${ }^{13}$ Me refiero al trabajo de Verónica Gago en (2014) en el cual enfatiza modos de trabajos nn oficialase
al orden neodiberal. do neoliberal. ${ }^{13}$ Como contracorriente que subvierte este mercado, el trabajo travesti interroga los modelos de acumulación que opera bajo una lógica de reificación. En este descentramiento de la lógica de producción se encuentra también una interrogación de la futurización lineal de las lógicas de reproducción.

En el testimonio de la voz narradora se encuentra su posicionamiento fuera del núcleo de la familia tradicional, marco cristiano-normativo, que proclama la futurización de la especie humana mediante el coito vaginal y la figura del primogénito, como se ha señalado. Producción y reproducción, de este modo, quedan desarticulados. El travestismo como diferencia sexual y alteridad de género suspende la reglamentación de los cuerpos, develando otra economía de cuerpos constituyentes de la formación del estado-nación. Indica también que, aunque aparecerse en público significa poner en peligro la estratificación de la norma social, toda transacción disidente guiado por el deseo, por remuneración monetaria o por diversión y placer, apunta sobre otros modos de habitar el mundo. Así, el deseo travesti-trans, a través del acto de travestirse y de corporeizar disidencia, apunta hacia una autonomía de ser y transformarse, de guiar la vida cotidiana hacia el futuro 


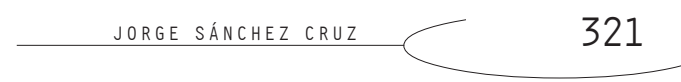

por medio de la transgresión de expectativas hegemónicas.

De ir de venir y de futurizarse en lo que "une va siendo".

\section{POR OTRO MUNDO DE POSIBLES}

Si bien Halberstam describe que cada persona trans

tiene el derecho de generar sus propias categorizaciones

y Wayar describe cómo hacer una Nostredad entre travestis y personas trans, el texto de Mario Bellatin resalta ese pequeño mundo de posibles, desplazado a los márgenes (el salón posicionado geográficamente afuera de la urbe) y forzado así a vivir en las orillas de la ciudadanía. He ahí, en la periferia, donde el texto literario saca a la luz otra manera de vivir y de habitar el mundo; otro modo de ser y de hacerse posible, desterritorializándose de lo que se llama el género y sus diferentes vectores (corporal, sexual, racial y económico) que excluyen la diferencia. Lo trans, en este sentido, como prefijo siempre en movimiento y como modo de ser (y de hacerse y re-hacerse) invita a transformar lo dado como aceptado, moviéndolo hacia otros modos de corporeizar sexo y sexualidad; es decir, lo trans - en sus diferentes manifestaciones y sus modalidades de desestabilizar el género (el travestismo, lo travesti, y los sujetos trans en sí) - aparece como transfiguración de los marcos de legibilidad, proponiendo así una transformación política que no solo cambie los códigos civiles y jurídicos del estado-nación, sino que igual toque a cada une 
para re-pensar el modo de aproximarse al otre que posa y corporeiza una alteración identitaria. Salón de belleza, en este aspecto, juega con su lector forzándolo a aquedar en la duda, sin saber del todo la identidad, el cuerpo, o el deseo de sus protagonistas. Así, la literatura tiene el potencial de desarticular las normas de lo social, vislumbrando la posibilidad de construir otro tipo de mundo, ahí donde otros posibles - cuerpos, seres, sujetos y personas - potencialicen su existencia.

\section{Bibliografía}

BAUdrillard, J. (2017). Simulacra and Simulation. Ann Arbor, Michigan: University of Michigan Press.

Bellatin, M. (1999). Salón de belleza. México, D.F.: Tusquets Editores.

Berkins, L. y Fernandez, J. (2006). La gesta del nombre propio. Buenos Aires: Editorial Madres de Plaza de Mayo.

Butler, J. (1993). Bodies that Matter. On the Discursive Limits of "Sex". NewYork/London: Routledge.

CHEN, M. (2012). Animacies: Biopolitics, Racial Mattering, and Queer Affect. Durham: Duke University Press.

De Certeau, M. (1984). The Practice of Everyday Life. Berkeley/Los Angeles: University of California Press.

Delgado, S. (2011). Estética, política y sensación de la muerte en Salón de belleza de Mario Bellatin. Revista Hispánica Moderna, 64(1), 69-79. DEUTSCHER, P. (2017). Foucault's Futures: A Critique of Reproductive Reason. New York: Columbia University Press. 


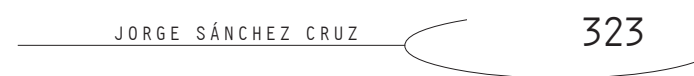

DiPietro, P. (2015). Decolonizing travesti space in Buenos Aires: race, sexuality, and sideways relationality. Gender, Place, and Culture: $A$ Journal of Feminist Geography, 23(5), 677-693. https://doi.org/10.1080/ 0966369X.2015.1058756

DiPietro, P. (2016). Of Huachafería, Así, and M' e Mati. Decolonizing Transing Methodologies. TSQ: Transgender Studies Quarterly, 3(1-

2), 65-73. https://doi.org/10.1215/23289252-3334211

EdeLMAN, L. (2004). No Future. Queer Theory and the Death Drive. Durham: Duke University Press.

ENG, D. (2010). The Feeling of Kinship: Queer Liberalism and the Racialization of Intimacy. Durham: Duke University Press.

GAGO, V. (2014). La razón neoliberal: economías barrocas y pragmática popular. Buenos Aires: Tinta Limón.

GuATtARI, F. (2013). Líneas de fuga: por otro mundo de posibles. Buenos Aires: Editoral Cactus.

HALBERSTAM, J. (2017). Trans: A Quick and Quirky Account of Gender Variability. Oakland: University of California Press.

KULAWIK, K. (2009). Travestismo lingüístico: el enmascaramiento de la identidad sexual en la narrativa latinoamericana neobarroca. Madrid: Iberoamericana-Vervuert.

KULAWIK, K. (2012). Des-escribir el hombre y la mujer: la performance en la sexualidad enmascarada en algunas novelas de Bellatin. En C. Gronemann y C. Sieber (Eds.), Fiestas infinitas de máscara: actos performativos de feminidad y masculinidad en México (pp. 169-183). Hildesheim: Goerge Olms Verlag. 
Lefebvre, H. (1991). The Production of Space. Malden: Blackwell.

Lugones, M. (2008). The Coloniality of Gender. Worlds \& Knowledges

Otherwise, 2, 1-17.

Lugones, M. (2017). Heterosexualism and the Colonial/Modern Gender System. Hypatia, 22(1), 186-209. https://www.muse.jhu.edu/article/ 206329

Meruane, L. (2012). Viajes Virales. La crisis del contagio global en la escritura del sida. Santiago: Fondo de Cultura Económica.

Molzoy, S. (2012). Poses de fin de siglo: Desbordes del género en la modernidad. Buenos Aires: Eterna Cadencia.

MuÑoz, J. E. (1999). Disidentifications. Queers of Color and the Performance of Politics. Minneapolis: University of Minnesota Press.

Perlongher, N. (1999). El negocio del deseo: la prostitución masculina en San Pablo. Buenos Aires: Paidós.

PuAR, J. (2015). Bodies with New Organs: Becoming Trans, Becoming Disabled. Social Text, 124 33(3), 45-73. https://doi.org/10.1215/016424723125698

SARDUY, S. (1969). Escritos sobre un cuerpo. Buenos Aires: Sudamericana. SARDUY, S. (1982). La simulación. Caracas: Monte Avila Editores.

Sifuentes-JÁUREgUI, B. (2002). Transvestism, Masculinity, and Latin American Literature. New York: Palgrave.

VAGGIONE, A. (2009). Literatura/enfermedad: el cuerpo como desecho. Una lectura de Salón de belleza de Mario Bellatin. Revista Iberoamericana, 75(227), 475-486. https://doi.org/10.5195/ reviberoamer.2009.6585 


\section{JORge SÁnChez CRUZ $\quad 325$}

WAYAR, M. (2019). Travesti. Una teoría lo suficientemente buena. Buenos

Aires: Muchas Nueces. 